\title{
Comparative Study on the Chronic Vascular Responses Induced by Regular Versus Occasional Waterpipe Smoke Inhalation in Mice
}

\author{
Naserddine Hamadia Sumaya Beegam ${ }^{b} \quad$ Nur Elena Zaaba ${ }^{b} \quad$ Ozaz Elzaki ${ }^{b}$ \\ Badreldin H. Alic Abderrahim Nemmar ${ }^{\mathrm{b}, \mathrm{d}}$

\begin{abstract}
aDepartment of Life and Environmental Sciences, College of Natural and Health Sciences, Zayed Health Sciences, United Arab Emirates University, Al Ain, United Arab Emirates, 'Department of Pharmacology and Clinical Pharmacy, Sultan Qaboos University, Muscat, Al-Khod, Oman, 'Zayed Center for Health Sciences, United Arab Emirates University, Al Ain, United Arab Emirates
\end{abstract} \\ University, Abu Dhabi, United Arab Emirates, bDepartment of Physiology, College of Medicine and
}

\section{Key Words}

Waterpipe smoke regimen - Oxidative stress - Inflammation - Thrombogenicity • Vascular alterations

\begin{abstract}
Background/Aims: Waterpipe smoke (WPS) is the second most prevalent form of smoking in the world. There are ample evidences about the vascular alterations caused by regular WPS (Reg-WPS). Nonetheless, comparison of the chronic vascular response induced by regular versus occasional WPS (Occ-WPS) exposure is very scarce. Methods: We investigated, in BALB/C mice, the effects of Occ-WPS (30 minutes/day, 1 day/week) versus Reg-WPS (30 minutes/day, 5 days/week) for 6 months on thrombogenicity and platelet aggregation in vivo and in vitro. Moreover, various markers of endothelial integrity, inflammation and oxidative stress were assessed by enzyme-linked immunosorbent assay and colorimetric assay. Control mice were exposed to air. Results: Our results showed that either Occ-WPS or Reg-WPS exposure shortened the thrombotic time in pial microvessels in vivo. Moreover, in pial venules, this effect was more marked in Reg-WPS group (-47\%) compared with Occ-WPS (-34\%). Similarly, exposure to either Occ-WPS or Reg-WPS reduced the prothrombin time and activated partial thromboplastin time. Platelet count was increased only in Reg-WPS exposure. Exposure to either Occ-WPS or Reg-WPS induced platelet aggregation in vitro. In addition, there was a statistically significant difference between Occ-WPS and Reg-WPS groups in platelet count and aggregation. Plasma concentration of tissue factor (+98\%), P-selectin $(+14 \%)$ and E-selectin (+16\%) were significantly increased in Occ-WPS group compared with air exposed group. Likewise, compared with air group Reg-WPS caused an increase in

Professor A. Nemmar United Arab Emirates University, College of Medicine and Health Sciences, Department of Physiology P.O. Box 17666, Al Ain (United Arab Emirates)

Tel.+971-37137533, Fax+9713 7671966, E-Mail anemmar@uaeu.ac.ae; anemmar@hotmail.com
\end{abstract}


concentration of tissue factor (+193\%), P-selectin (+21\%) and E-selectin (+42\%). Nevertheless, only Reg-WPS induced a decrease (-38\%) in the plasma concentration of tissue plasminogen activator. Notably, our results showed a statistically significant difference between Occ-WPS and Reg-WPS groups in the concentration of tissue factor. Erythrocyte numbers, hemoglobin concentration, hematocrit and lactate dehydrogenase activity were augmented only in Reg-WPS group compared with either control or Occ-WPS groups. Likewise, only Reg-WPS induced an increase in proinflammatory cytokines, tumor necrosis factor- $\alpha$ and interleukin$1 \beta$ compared with either control or Occ-WPS groups. However, markers of oxidative stress including 8-isoprostane and total antioxidants were enhanced in both Occ-WPS and RegWPS compared with control group. Conclusion: Our data confirm the vascular toxicity of the chronic Reg-WPS exposure and shows that even occasional chronic exposure to WPS caused thrombosis, platelet aggregation, endothelial alterations and oxidative stress. The latter findings are an additional cause of concern about the long-term toxicity of occasional waterpipe smoking.

\section{Introduction}

Hookah also known as waterpipe, narghile, argileh, shisha, hubble-bubble, goza, borry, qaylan, chica, and mada'a is a form of traditional smoking made of tobacco pipe with a long stretchy tube that draws the smoke through water contained in a bowel [1]. This practice is ceased to be a middle-eastern culture where we can find it around bars in college campuses in the western hemisphere such as the United States and Europe [2]. The popularity of WPS is rising among trendy youth, university students, and even high-school-aged children [3, 4]. There is an erroneous belief among WPS smokers that WPS is less harmful compared with cigarette smoking (CS) [5], and this is based on the misconception that the filtration occurs when the smoke passes through the water will diminish the levels of tar, nicotine, and other toxins [6]. A meta-analysis conducted by Neergaard et al. suggested that daily WPS generates nicotine equivalent to daily smoking of 10 cigarettes. Furthermore, occasional WPS is comparable to smoking two cigarettes during 24-hr [7]. There are increasing epidemiological evidences suggesting the potential of WPS of becoming a major public health problem in most Arab countries [8].

According to the 2015 WHO recommendation and several other reports, WPS probably is addictive as in other forms of tobacco and its consumption may lead to the same detrimental effects caused by cigarette [1, 9-11]. In support of the latter, it has been reported that WPS contains ample quantities of toxicants including nicotine, tar, carbon monoxide, polycyclic aromatic hydrocarbons, nitrosamines, volatile aldehydes, phenols and heavy metals, catechol and hydroquinone $[9,10]$. Clinical and experimental studies including our own, demonstrated that WPS causes various diseases and is detrimental to various systems comparable to cigarette smoke, including cancer [10,12], reproductive system injuries [13], adverse cardiopulmonary effects [14] and metabolic syndrome development which is considered a major risk factor for developing thrombosis $[15,16]$. Furthermore, it leads to low birth weight $[17,18]$ and increased neonatal death rate $[19]$.

It has been reported that occasional or regular WPS users are susceptible to be regular cigarette smokers, signifying the fact that WPS may be a potential leading way for CS smoking [20]. Most of the research on smoking focused on regular smoking. However, recent population data indicate that $22 \%-33 \%$ of US adult smokers are intermittent smokers who do not smoke every day [21,22]. Moreover, the number of non-daily smokers is anticipated to rise due to the high cost of tobacco and restriction rules in public areas $[23,24]$. The classification of occasional smokers is based on the amount and frequency of smoking. The latter includes four categories, (1) smoking two days in the past week, (2) smoking at least 100 cigarettes in their lifetime, but not smoking daily and having smoked in the last 12 months, (3) smoking between 1 and 10 cigarettes per day in the last 30 days, or (4) smoking at least once a week but not every day $[25,26]$. 


\section{Cellular Physiology Cell Physiol Biochem 2022;56:13-27 \\ \begin{tabular}{l|l}
\hline DOI: 10.33594/000000491 & (c)22 The Author(s). Published by
\end{tabular} \\ and BIOChemistry Published online: 19 January 2022 Cell Physiol Biochem Press GmbH\&Co. KG \\ Hamadi et al.: Waterpipe Smoking Regimen and Vascular Responses}

Accumulating evidences suggest that light and non-daily cigarette smoking are associated with increased morbidity including a similar risk of cardiovascular diseases as heavier smokers, different types of cancer, respiratory diseases and reproductive health problems [27-31]. Hence, as far as we are aware, there is a scarcity of data on the vascular and systemic effects of occasional WPS and in order to address that, we aimed to investigate the mechanisms underlying the effects of six months exposure to either Occ-WPS (30 minutes/ day, 1 day/week) or Reg-WPS (30 minutes/day, 5 days/week) on thrombogenicity, platelet aggregation, endothelial integrity, inflammation, and oxidative stress.

\section{Materials and Methods}

Animals and WPS exposure

BALB/c mice of both genders aged 6-8 weeks, weighing 20-25 g (Taconic Farms Inc., Germantown, NY, USA) were housed in the local central animal facility of the College of Medicine and Health Sciences and maintained in controlled light cycle (12-h light:12-h dark cycle), humidity of $60 \%$ and, controlledtemperature $\left(22 \pm 1^{\circ} \mathrm{C}\right)$. Animals had free access to water and food ad libitum.

After one week of acclimatization to the experimental conditions, the mice were indiscriminately separated into 3 groups, air (control), Occ-WPS and Reg-WPS. The WPS exposure protocol has been performed according to previously described methods [32,33]. Mice were placed in soft restraints and connected to the exposure tower. Using a nose-only exposure system connected to a waterpipe device, the animals were exposed to either air or WPS by their noses (inExpose System, SCIREQ, Canada). Animals were exposed to mainstream WPS generated by commercially available apple-flavored tobacco. For each daily session, 10 grams of tobacco were placed into the WPS head. At the end of WPS exposure session, the remaining tobacco was discarded.

Control mice were exposed to air only. The duration of the session was $30 \mathrm{~min} /$ day. Regarding Reg-WPS, mice were exposed to WPS, 5 days/wk for 6 months [32, 33] and for Occ-WPS group, mice were exposed to WPS, 1 day/wk for 6 months. The WPS exposure procedure was monitored by a computerized system. A computer-monitored puff was produced every $1 \mathrm{~min}$ (consisting of a $2 \mathrm{~s}$ puff time of WPS after that a $58 \mathrm{~s}$ of fresh air). Twenty-four hours following the last exposure session, various vascular endpoints were assessed. The total number of animals used in the present study was 83 . They were distributed as described below.

\section{Induction of thrombosis in pial arterioles and venules of mouse photochemically}

In vivo pial arteriolar and venular thrombogenesis was assessed in separate set of mice at the end of the 6 months exposure period to either Occ-WPS ( $n=6)$ or Reg-WPS (n=7) or air $(n=7)$, according to a previously described technique [32,33]. Briefly, the trachea was intubated after the induction of anesthesia with urethane (1 mg/g body wt ip), and a 2-Fr venous catheter (Portex, Hythe, UK) was inserted in the right jugular vein for the administration of fluorescein (Sigma- Aldrich). Thereafter, a craniotomy was first performed on the left side, using a microdrill, and the dura was stripped open. Only untraumatized preparations were used, and those showing trauma to either the microvessels or underlying brain tissue were discarded. Animals were then placed on the stage of a fluorescence microscope (Olympus, Melville, NY) attached to a camera and DVD recorder. A heating mat was placed under the mice, and body temperature was raised to $37^{\circ} \mathrm{C}$, as monitored by a rectal thermoprobe connected to a temperature reader (Physitemp Instruments). The cranial preparation was moistened continuously with artificial cerebrospinal fluid of the following composition (in mM): $23 \mathrm{NaHCO}_{3}, 5 \mathrm{KCl}, 3 \mathrm{NaH}_{2} \mathrm{PO}_{4}, 4 \mathrm{MgSO}_{4}, 124 \mathrm{NaCl}, 2.5 \mathrm{CaCl}$, and 10 glucose (pH 7.3-7.4). A field containing arterioles and venules of 15-20 $\mu \mathrm{m}$ in diameter was chosen. Such a field was taped before and during the photochemical insult. The photochemical insult was carried out by injecting fluorescein $(0.1 \mathrm{ml} /$ mouse of $5 \%$ solution) via the jugular vein, which was allowed to circulate for 30-40 s. The cranial preparation was then exposed to stabilized mercury light. This combination produces endothelium injury of the arterioles and venules. This, in turn, causes platelets to adhere at the site of endothelial damage and then aggregate. The platelet aggregates and thrombus formation grow in size until complete arteriolar or venular occlusion. The time from the photochemical injury until full vascular occlusion (time to flow stop) in arterioles and venules was measured in seconds. At the end of the experiments, animals were euthanized by an overdose of urethane. 


\section{\begin{tabular}{ll} 
Cellular Physiology & Cell Physiol Biochem 2022;56:13-27 \\
\hline DOl: 10.33594/000000491 & 2022 The Author(s). Published by
\end{tabular} and Biochemistry \begin{tabular}{l|l} 
Pul: 10.33594/000000491 & $\begin{array}{l}\text { C } 2022 \text { The Author(s). Published by } \\
\text { Cell Physiol Biochem Press GmbH\&Co. KG }\end{array}$ \\
\hline
\end{tabular}}

Prothrombin time (PT) and activated partial thromboplastin time (PTT) measurement in plasma in vitro

In a separate set of mice, at the end of the 6 months exposure period to either Occ-WPS $(n=6)$ or RegWPS ( $n=6)$ or air $(n=7)$, animals were anesthetized, and the blood was withdrawn from the inferior vena cava and placed in citrate solution (3.2\%) (ratio of the blood to anticoagulant: 9:1) for PT and aPTT measurement according to a previously described technique $[32,33]$. The PT was measured on freshly collected plateletpoor plasma with human relipidated recombinant thromboplastin (Recombiplastin, Instrumentation Laboratory, Orangeburg, NY) in combination with a Merlin coagulometer (MC 1 VET, Merlin). The aPTT was measured with automated aPTT reagent from bioMerieux (Durham, NC) using a Merlin coagulometer (MC 1 VET, Merlin). Normal plasma used as the reference for both PT and aPTT was prepared by pooling equal portions of platelet-poor plasmas from the blood of seven untreated mice.

\section{Platelet aggregation in mouse whole blood}

The platelet aggregation assay in whole blood obtained from a separate set of mice exposed to OccWPS ( $n=7)$ or Reg-WPS ( $n=7)$ or air $(n=6)$ for 6 months was performed as described before [32,33]. After anesthesia, the blood was withdrawn from the vena cava and placed in citrate (3.2\%). Aliquots of $100 \mu \mathrm{l}$ were added to the wells of a Merlin coagulometer (MC 1 VET, Merlin, Lemgo, Germany). After incubation with ADP $(1 \mu \mathrm{M})$ for $3 \mathrm{~min}$ at $37.2^{\circ} \mathrm{C}$, Blood samples were stirred for $3 \mathrm{~min}$. At the end of this period, $25 \mu \mathrm{l}$ samples were removed and fixed on ice in $225 \mathrm{ml}$ cellFix (Becton Dickinson, Franklin Lakes, NJ). ADP induction of platelet aggregation is reflected by a decrease in counted single platelets in the blood obtained from Occ-WPS or Reg-WPS or air-exposed mice.

Measurement of tissue factor, tissue plasminogen activator (tPA), P-selectin and E-selectin concentrations in the plasma

The concentrations of tissue factor, P-selectin and E-selectin in the plasma obtained from mice exposed to Occ-WPS ( $\mathrm{n}=8)$ or Reg-WPS ( $\mathrm{n}=8)$ or air $(\mathrm{n}=8)$ were measured by enzyme-linked immunosorbent (ELISA) assays using commercially available kits obtained from R\&D systems (Duo Set, Minneapolis, MN, USA). Regarding tPA, the ELISA kit was obtained from Molecular Innovations (Novi, Michigan, USA).

\section{Blood count}

Erythrocyte and platelet count, hemoglobin concentration and hematocrit were assessed in the same mice reported above. The animals were anesthetized intraperitoneally with pentobarbital sodium (45 mg/kg), and blood was then drawn from the inferior vena cava in EDTA (4\%). A sample was used for platelet and red blood cell counts and hematocrit determination using an ABX VET ABC Hematology Analyzer with a mouse card (ABX Diagnostics, Montpellier, France). The remaining blood was centrifuged for $15 \mathrm{~min}$ at $4^{\circ} \mathrm{C}$ at $900 \mathrm{~g}$, and the plasma samples obtained were stored at $-80^{\circ} \mathrm{C}$ until further analysis.

Measurement of lactate dehydrogenase (LDH) activity in the plasma

The LDH activity was measured using commercial kits (Sigma Chemical, St. Louis, MO, USA) which determine the conversion of lactate to pyruvate in the presence of $\mathrm{LDH}$ with an equivalent lessening of NAD in the plasma of the mice reported above. The formation of NADH from the reaction can show a difference when measured in absorbance at $340 \mathrm{~nm}$.

Measurement of $T N F \alpha, I L-1 \beta, 8$-isoprostane and total antioxidant capacity levels in the plasma

The proinflammatory and oxidative stress markers were assessed in the plasma of the mice reported above. The concentration of the pro-inflammatory cytokines, tumor necrosis factor- $\alpha$ (TNF $\alpha$ ) and interleukin-1 $\beta$ (IL-1 $\beta$ ) were measured by ELISA assays using commercially available kits obtained from R\&D systems (Duo Set, Minneapolis, MN, USA). Protein content in each sample was measured by Bradford's method, as described earlier [32, 33].

The levels of 8-isoprostane and total antioxidants were quantified according to the manufacturer's instructions provided in the commercially available assay kits obtained from Cayman Chemicals (Michigan, USA). 


\section{Cellular Physiology Cell Physiol Biochem 2022;56:13-27 \\ \begin{tabular}{ll|l} 
and Biochemistry & $\begin{array}{l}\text { DOl: 10.33594/000000491 } \\
\text { Published online: 19 January 2022 }\end{array}$ & $\begin{array}{l}\text { O } 2022 \text { The Author(s). Published by } \\
\text { Cell Physiol Biochem Press GmbH\&Co. KG }\end{array}$ \\
\cline { 2 - 3 } &
\end{tabular} \\ Hamadi et al.: Waterpipe Smoking Regimen and Vascular Responses}

Statistical analysis

All graphs were produced using GraphPad Prism Version 7 for Windows software (GraphPad Software Inc, San Diego, CA, United States). Data were expressed as means \pm SEM. To assess whether the measured parameters were normally distributed, the Shapiro-Wilk normality test was used. Normally distributed data were tested by using one-way analysis of variance ANOVA followed by Holm-Sidak's multiple comparisons test. $\mathrm{P}<0.05$ was considered significant.

\section{Results}

Photochemically induced thrombosis in pial arterioles and venules of mouse in vivo

Fig. 1 shows the effect of Occ-WPS or Reg-WPS exposure on photochemically induced thrombosis in both pial arterioles and venules of mice. The exposure to either Occ-WPS or RegWPS showed a prothrombotic tendency in both pial arterioles and venules. Compared with air-exposed mice, the occlusion time in pial arterioles was significantly shortened following exposure to either Occ-WPS $(\mathrm{P}<0.00001)$ or Reg-WPS $(\mathrm{P}<0.00001)$ (Fig. 1A). Similarly, in pial venules, Occ-WPS $(\mathrm{P}<0.00001)$ or Reg-WPS $(\mathrm{P}<0.00001)$ caused a marked reduction of the thrombotic occlusion time. Moreover, in the pial venules there was a statistical significance between Occ-WPS and Reg-WPS groups ( $<<0.00001)$ (Fig. 1B).

\section{PT and aPTT}

Fig. 2 illustrates the impact of 6 months exposure to either Occ-WPS or Reg-WPS on PT and aPTT in mouse plasma. The shortening of PT and aPTT is indicative of hypercoagulability tendency in the blood. The exposure to Occ-WPS or RegWPS induced a statistically significant shortening of PT $(\mathrm{P}<0.00001$, Fig. $2 \mathrm{~A})$ and aPTT $(\mathrm{P}<0.00001$, Fig. 2B) compared with plasma obtained from air-exposed mice.

\section{Platelet numbers and platelet aggregation in vitro}

As shown in Fig. 3A, Occ-WPS exposure did not affect platelet number in the blood compared with air exposed group. However, Reg-WPS exposure induced significant increase in the platelet numbers $(\mathrm{P}=0.03)$. In addition, there was a statistically significant increase in the number of platelets in Reg-WPS group compared with Occ-WPS one $(\mathrm{P}=0.04)$. We found that whole blood obtained from mice exposed to either Occ-WPS or Reg-WPS and incubated in vitro with $\mathrm{ADP}$ displayed a significant platelet aggregation $(\mathrm{P}=0.005-\mathrm{P}=0.00001)$ compared with blood collected from mice exposed to air. Moreover, there was a statistical significance between Occ-WPS and Reg-WPS groups ( $\mathrm{P}=0.005)$ (Fig. 3B).

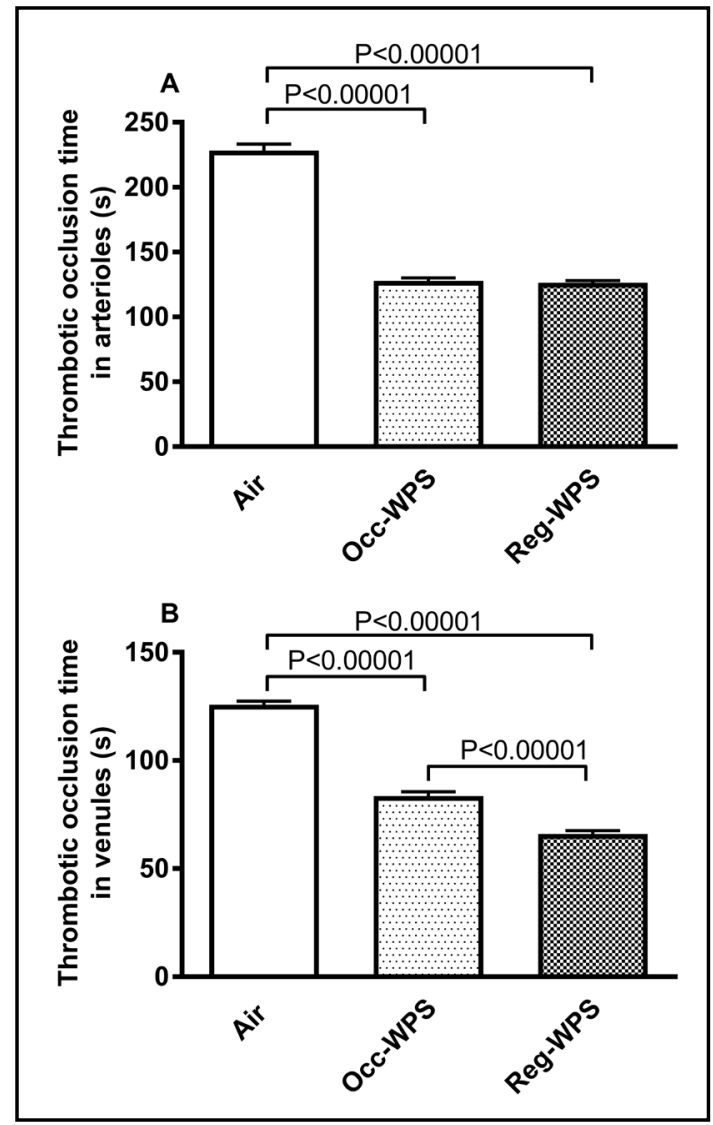

Fig. 1. Thrombotic occlusion time in pial arterioles (A) and venules (B) at the end of 6 months exposure to air, occasional waterpipe smoking (Occ-WPS) or regular WPS (Reg-WPS). Data are mean \pm SEM $(n=6$ 7). 


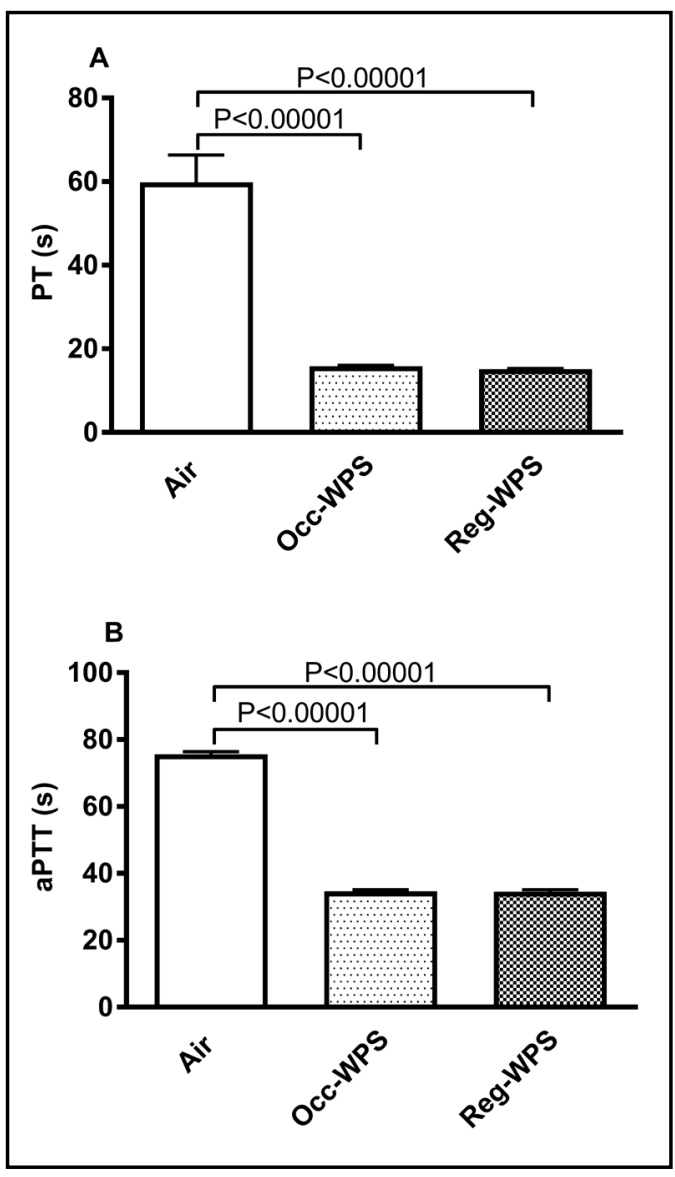

Fig. 2. Prothrombin time (PT, A) and activated partial thromboplastin time (aPTT, B) in vitro at the end of 6 months exposure to air, occasional waterpipe smoking (Occ-WPS) or regular WPS (RegWPS). Data are mean \pm SEM $(n=6-7)$.

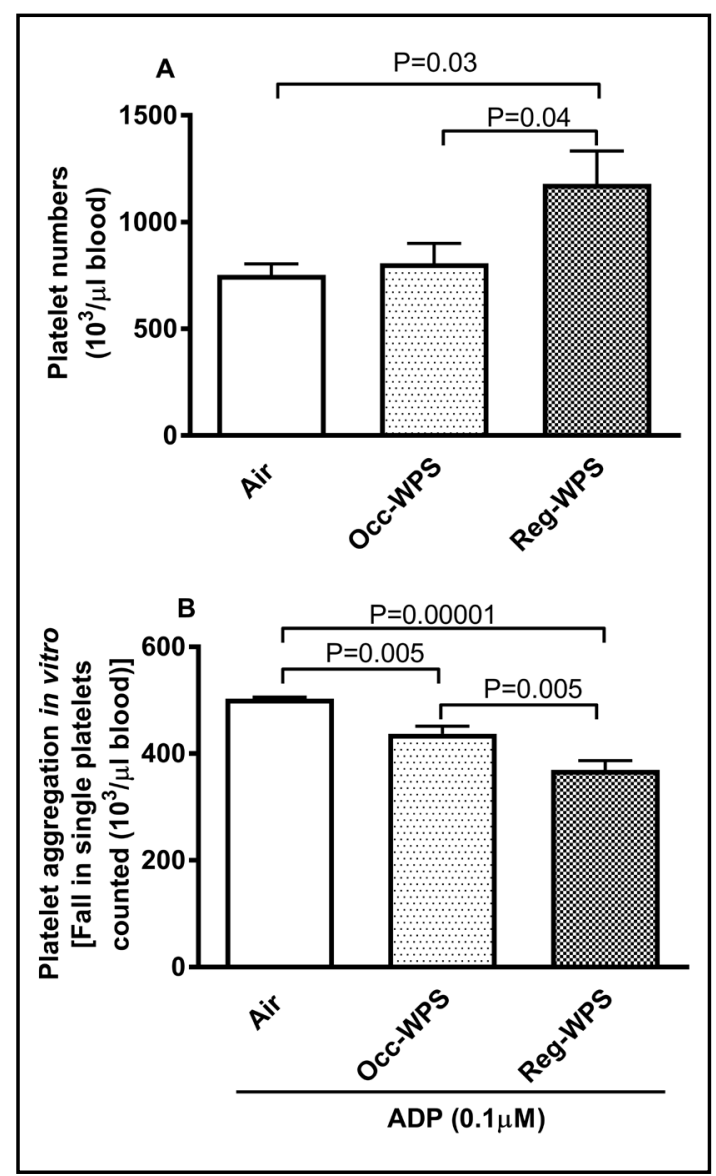

Fig. 3. Platelet numbers (A) and in vitro platelet aggregation (B) in whole blood at the end of 6 months exposure to air, occasional waterpipe smoking (OccWPS) or regular WPS (Reg-WPS). Platelet aggregation was quantified by measuring the fall in single platelets counted due to aggregation induced by $0.1 \mu \mathrm{M}$ of ADP. Data are mean \pm SEM $(n=6-8)$.

\section{Concentrations of tissue factor, $t P A, P$-selectin and E-selectin in the plasma}

Fig. 4 exemplifies the effect of Occ-WPS or Reg-WPS on the plasma concentrations of tissue factor (Fig. 4A), tPA (Fig. 4B), P-selectin (Fig. 4C) and E-selectin (Fig. 4D). Compared with air exposed group, exposure to Occ-WPS or Reg-WPS caused a significant increase $(\mathrm{P}<0.00001)$ in tissue factor concentration in the plasma and there was statistical significance between Occ-WPS and Reg-WPS groups $(\mathrm{P}<0.00001)$. Regarding tPA, a significant reduction was observed only in the plasma of mice exposed to Reg-WPS $(\mathrm{P}=0.006)$. In addition, there was a statistical significance between Occ-WPS and Reg-WPS groups $(\mathrm{P}=0.02)$. The plasma concentrations of the adhesion molecule P-selectin were significantly increased following Occ-WPS $(\mathrm{P}=0.004)$ or Reg-WPS $(\mathrm{P}=0.0001)$ exposure compared to air exposed mice. In addition, the concentration of E-selectin was statistically increased in both Occ-WPS ( $\mathrm{P}=0.01)$ and Reg-WPS $(\mathrm{P}<0.00001)$ groups compared with air exposed mice. Moreover, there was a statistical significance in the concentration of E-selectin between Occ-WPS and Reg-WPS groups $(\mathrm{P}=0.0006)$. 


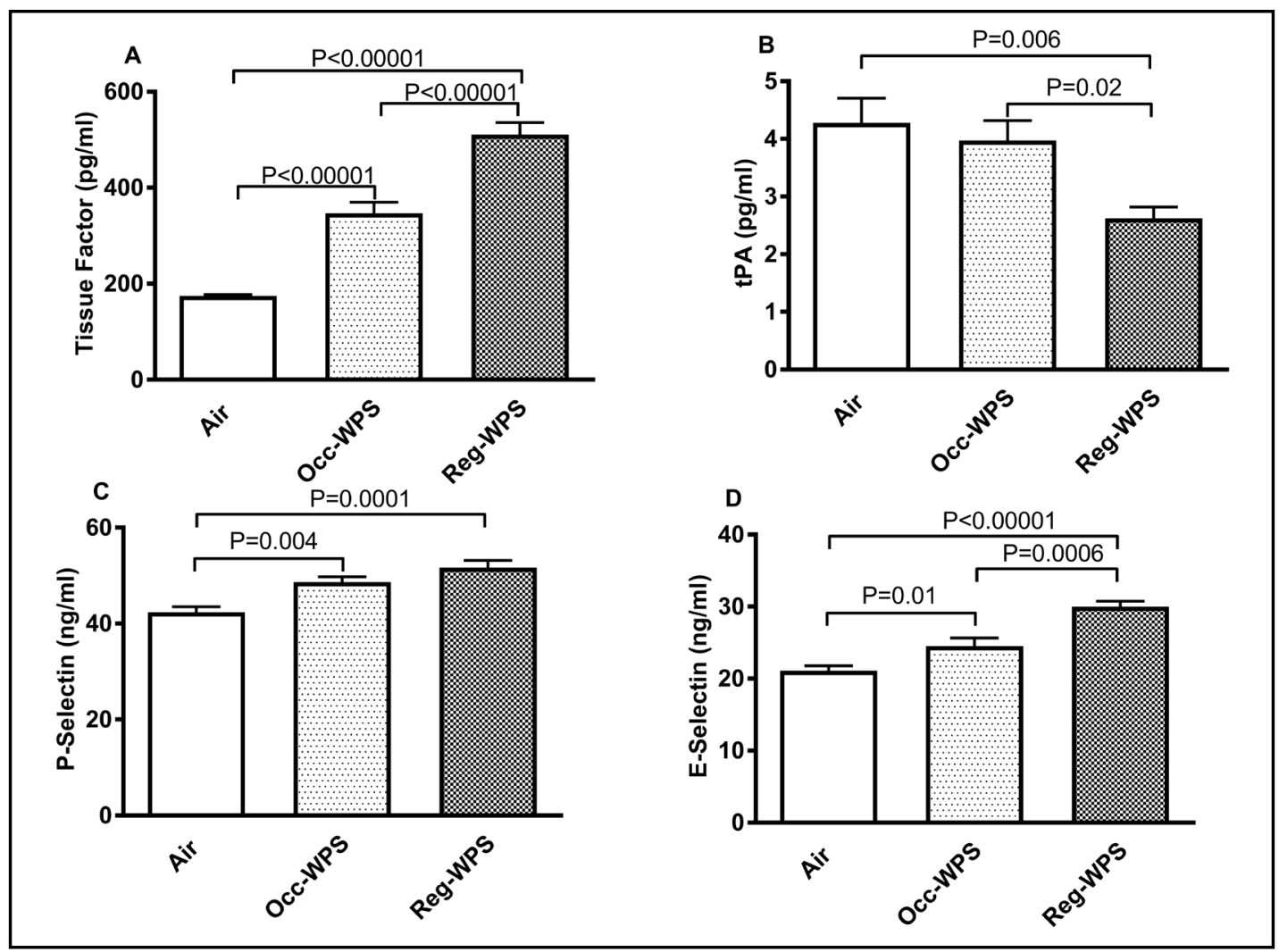

Fig. 4. Plasma concentrations of tissue factor (A), tissue plasminogen activator (tPA) (B), P-selectin (C) and E-selectin (D) at the end of 6 months exposure to air, occasional waterpipe smoking (Occ-WPS) or regular WPS (Reg-WPS). Data are mean \pm SEM $(n=8)$.

\section{Erythrocyte numbers, hemoglobin concentration, and hematocrit}

The erythrocyte numbers and hematocrit were not affected following Occ-WPS exposure for a period of 6 months compared to air exposed group. However, we observed a significant increase in the erythrocyte numbers $(\mathrm{P}=0.0004)$ and hematocrit $(\mathrm{P}=0.0002)$ following exposure to Reg-WPS (Fig. 5A and B). Similarly, as shown in Fig. 5C, hemoglobin concentration was only significantly increased ( $\mathrm{P}=0.003)$ in Reg-WPS (Fig. 5B) group compared with air-exposed mice. In addition, there was a statistical significance between Occ-WPS and Reg-WPS groups for erythrocyte numbers $(\mathrm{P}=0.02)$, hematocrit $(\mathrm{P}=0.01)$ and hemoglobin concentration $(\mathrm{P}=0.01)$.

\section{Lactate Dehydrogenase (LDH) activity in the Plasma}

Our results showed no statistical changes in LDH activity in the plasma of mice occasionally exposed to WPS compared with air exposed group. In contrast, we observed a significant increase $(\mathrm{P}=0.0001)$ in the activity of $\mathrm{LDH}$ in the plasma of mice regularly exposed to WPS for 6 months (Fig. 6). Moreover, there was a statistical significance between Occ-WPS and Reg-WPS groups (P=0.0001).

\section{Concentrations of pro-inflammatory cytokines in the plasma}

The concentrations of pro-inflammatory cytokines, TNF $\alpha$ and IL-1 $\beta$ are shown in Fig. 7. We observed that Occ-WPS exposure for a period of 6 months did not have a significant effect on the plasma concentrations of TNF $\alpha$ and IL-1 $\beta$ compared with air exposed group. On the contrary, compared with air exposed group, the concentration of $\mathrm{TNF} \alpha(\mathrm{P}=0.003)$ and IL-1 $\beta(P=0.0001)$ in the plasma were significantly increased following Reg-WPS exposure. Moreover, both TNF $\alpha(\mathrm{P}=0.007)$ and IL-1 $\beta(\mathrm{P}=0.0006)$ were significantly increased in RegWPS group compared with Occ-WPS group. 
Cellular Physiology Cell Physiol Biochem 2022;56:13-27 and Biochemistry

Fig. 5. Erythrocyte numbers (A), hematocrit (B) and hemoglobin concentration (C) at the end of 6 months exposure to air, occasional waterpipe smoking (OccWPS) or regular WPS (Reg-WPS). Data are mean \pm SEM $(\mathrm{n}=8)$.

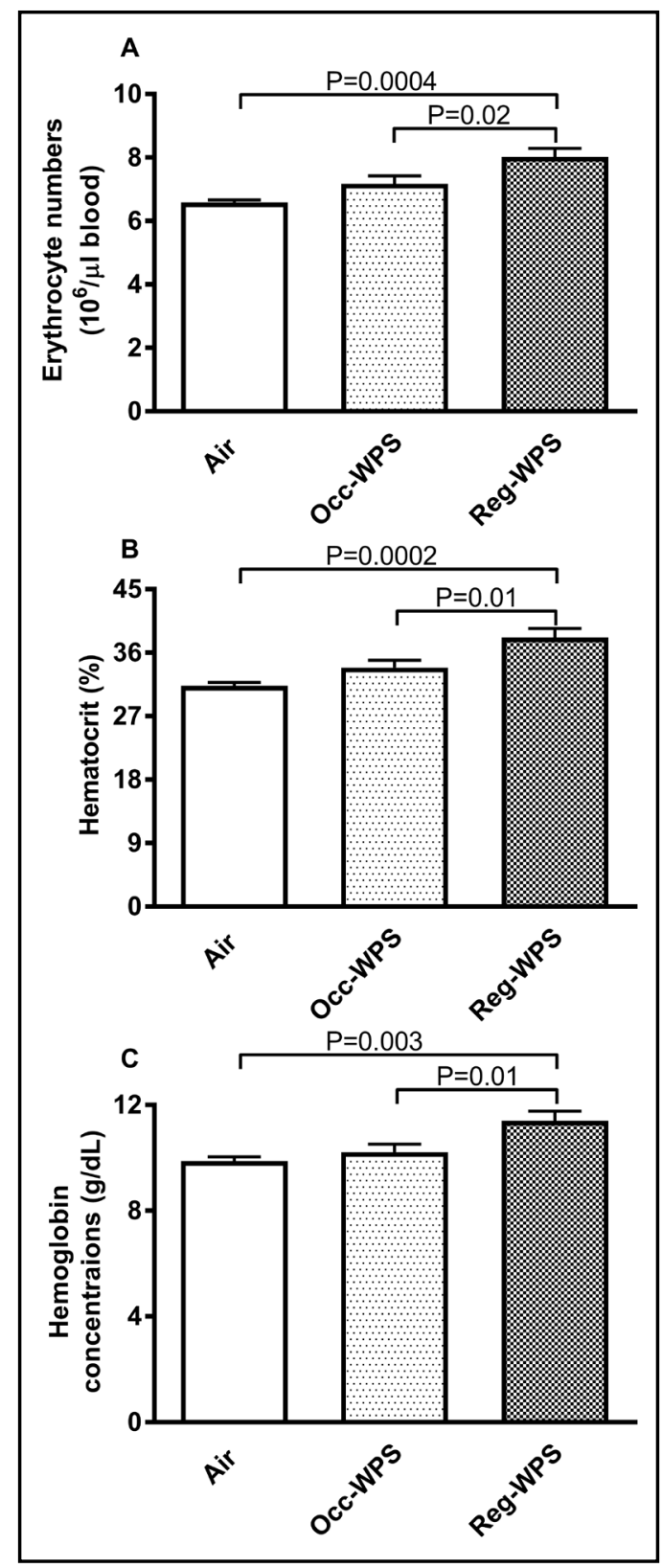

Fig. 6. Lactate Dehydrogenase (LDH) activity in the plasma at the end of 6 months exposure to air, occasional waterpipe smoking (Occ-WPS) or regular WPS (Reg-WPS). Data are mean \pm SEM $(n=8)$.

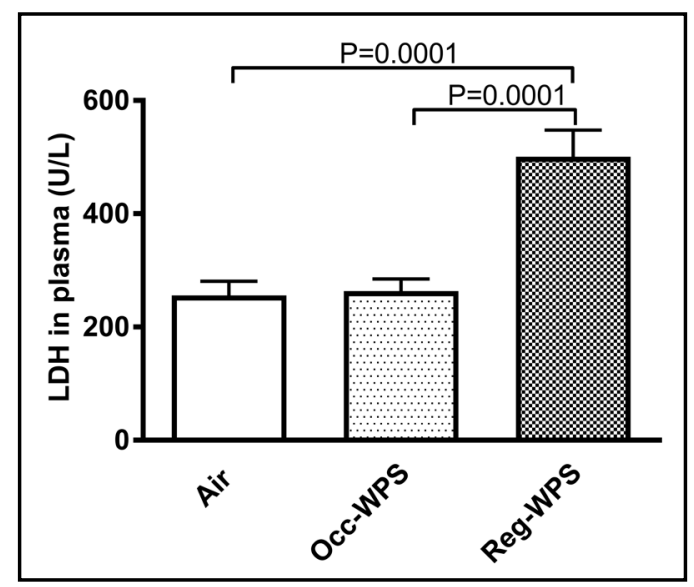




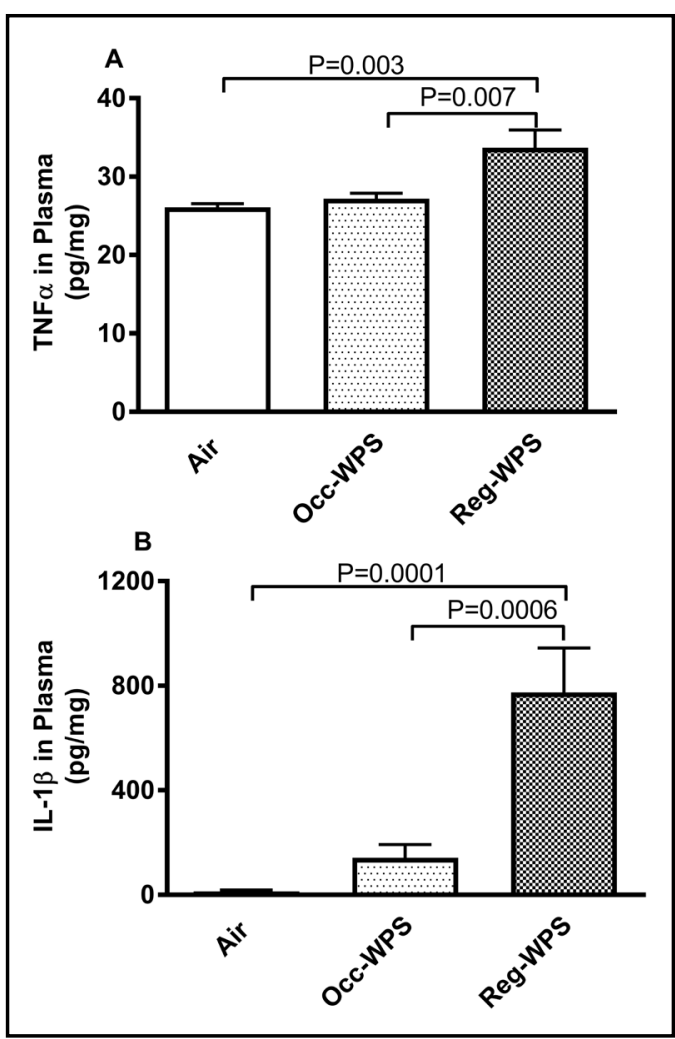

Fig. 7. Plasma concentrations of tumor necrosis factor $\alpha(\mathrm{TNF} \alpha)(\mathrm{A})$ and interleukin (IL)-1 $\beta$ (B) at the end of 6 months exposure to occasional waterpipe smoke (Occ-WPS) or regular WPS (Reg-WPS) or air. Data are mean \pm SEM $(n=8)$.

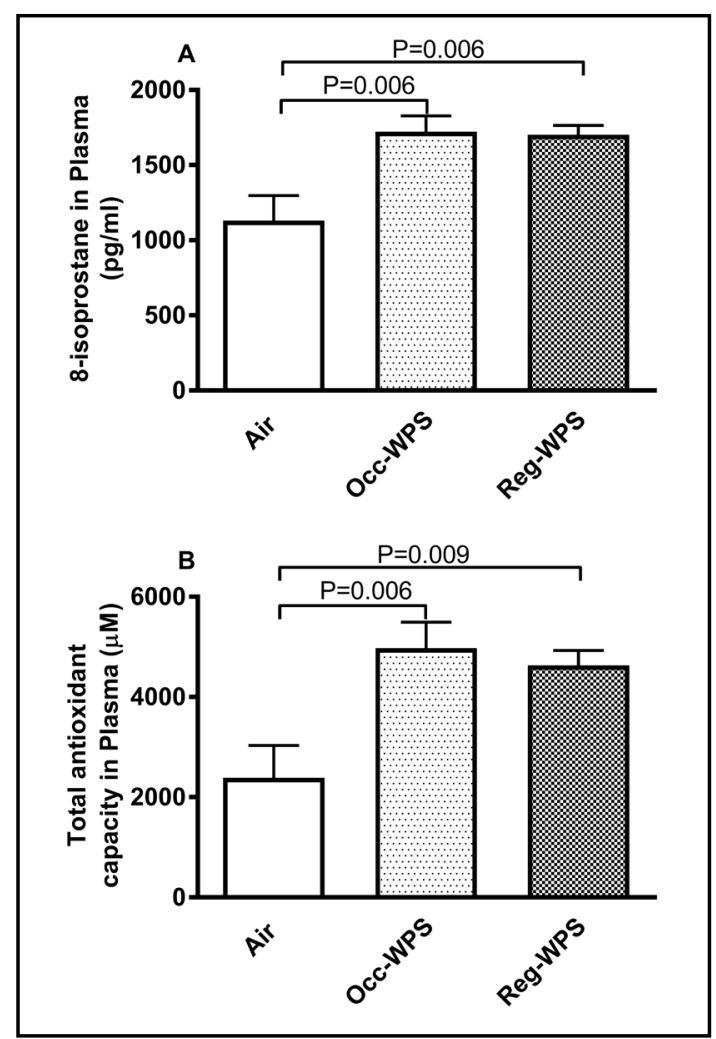

Fig. 8. Plasma levels of 8-isoprostane (A) and total antioxidant capacity (B) at the end of 6 months exposure to occasional waterpipe smoke (Occ-WPS) or regular WPS (Reg-WPS) or air. Data are mean \pm SEM $(n=6-8)$.

\section{Levels of Oxidative Stress Markers in the Plasma}

The quantification of the levels of 8-isoprostane and total antioxidants following OccWPS or Reg-WPS exposure is illustrated in Fig. 8. Our results showed that the concentration of 8-isoprostane, a marker of lipid peroxidation in the plasma were significantly increased following either Occ-WPS or Reg-WPS compared with air exposed group (P=0.006, Fig. 8A). Likewise, compared with air exposed group, exposure to either Occ-WPS $(\mathrm{P}=0.006)$ or RegWPS $(\mathrm{P}=0.009)$ induced a significant increase in total antioxidants capacity (Fig. 8B).

\section{Discussion}

The current study demonstrated that chronic Reg-WPS exposure triggers vascular toxicity and showed that even occasional chronic exposure to WPS caused thrombosis, platelet aggregation, endothelial alterations and oxidative stress.

Occasional smoking poses a real public health because it is always overlooked by the users due to numerous reasons that range from the erroneous perception that Occ-WPS is harmless to the fact that nicotine dependence can be escaped [34]. It is well known that intermittent or light smoking are associated with cardiopulmonary adverse effects and cancer [30,35]. While the chronic vascular effects of regular WPS exposure have been investigated, little is known about the possible effects of Occ-WPS on thrombogenicity, blood vessels integrity, inflammation and oxidative stress. 
It has been reported that smoking enhances systemic coagulability, through increasing circulating thrombin activity, fibrinogen levels and platelet activation [36]. As a novelty in the current work, our results show that either Occ-WPS or Reg-WPS exposure for a period of 6 months significantly shortened the thrombotic occlusion time in pial arterioles and venules in mice suggesting a prothrombotic impact of WPS regardless of the exposure regimen. Moreover, in pial venules, the thrombotic occlusion time was more markedly shortened in Reg-WPS group compared with Occ-WPS group. These findings provide evidence that WPS is not safe as the general misperception suggests. In line with our findings, it has been shown recently that acute exposure to WPS for 7 days increased the tendency to carotid artery thrombosis [37]. A similar effect was demonstrated following short-term exposure to e-cigarette [38, 39]. We have reported previously that short and long-term exposure to WPS leads to thrombogenicity [33, 40]. Clinically, it has been shown that smokers of waterpipe and cigarette had analogous degrees of endothelial dysfunction compared with nonsmokers [41].

Along with prothrombotic effects, we observed the shortening of PT and aPTT in mice following Occ-WPS or Reg-WPS exposure illustrating that Occ-WPS is as harmful as regular smoking in terms of blood hypercoagulability. Several studies including ours, evidenced the procoagulant effect of WPS [42]. Clinical studies have reported that smoking induces hypercoagulability state characterized by platelet count increase and shortening of PT and aPTT $[43,44]$.

It has been shown that cigarette smoke induces hemostatic disturbance through alteration in platelet aggregation $[45,46]$. Previously, we showed platelet aggregation after short-and long-term WPS exposure $[33,40]$. The current data show the numbers of circulating platelets were significantly increased in Reg-WPS and that both exposure regimens induced platelet aggregation in vivo. In addition, there was a statistical significance between Occ-WPS and Reg-WPS groups with a higher impact on platelets aggregation observed following RegWPS versus Occ-WPS exposure.

P-selectin and E-selectin are cell adhesion molecules that play a major role in the interaction of platelets and endothelial cells with neutrophils and monocytes [47]. Our data show that exposure to Occ-WPS is as effective as Reg-WPS in the enhancement of the plasma concentrations of P-selectin and E-selectin as platelet and endothelial activation markers respectively, suggesting an abnormal vascular reactivity [48]. Moreover, our results showed a higher concentration of E-selectin in Reg-WPS group compared with Occ-WPS group. This observation is well-matched with those of clinical studies that found a significant increase in systemic P-selectin concentration following exposure to conventional cigarettes or e-cigarette vapor with nicotine $[49,50]$. In line with the later, in vitro study showed cigarette smoke extract exposure caused an increase in the expression of the adhesion molecule E-selectin in human umbilical vein endothelial [49] and aortic endothelial cells [51, 52]. Moreover, an increase in the expression of E-selectin in the endothelium of human atherosclerotic lesions [51]. Taking these finding together, Occ-WPS or Reg-WPS exposure triggers the secretion of such adhesion molecules in the bloodstream indicating vascular damage and increased thrombosis. In line with our findings, a clinical study has reported that adolescents smoking waterpipe had significantly lower vascular endothelium growth factor levels which might adversely affect their vascular growth and function [53].

Our results show that both exposure regimens induced a significant increase in the concentration of tissue factor. Also, we observed a statistically significant increase in the concentration of tissue factor in Reg-WPS group compared with Occ-WPS group. This finding corroborates the finding of the experimental study that showed exposure to cigarette smoke increases immunoreactivity for tissue factor in animal model of the atherosclerotic plaques [36]. Moreover, an in vitro study showed the induction of tissue factor expression following the incubation of endothelial cells and smooth muscle cells with nicotine and cotinine [54].

Fibrinolysis is considered the main anticoagulation system that depends on the activity of tPA and plasminogen activator inhibitor-1 which are secreted from endothelial cells [55]. 
Diminished fibrinolytic activity manifested in low levels of tPA in smokers has also been reported in conditions associated with atherosclerosis [56]. Our data show that only RegWPS induced significant decrease in the concentration of tPA compared with either the control or Occ-WPS groups. This result corroborates previous findings which showed dysfunctional fibrinolytic system that was manifested in alterations in tPA release associated with cigarette smoking [57] and reduction in tPA concentration following the incubation of endothelial cells with serum collected from cigarette smokers [45]. Moreover, compared with nonsmokers and cigarette smokers, it has been demonstrated that waterpipe smokers had a significantly higher levels of plasma fibrinogen, a risk factor for cardiovascular disease [58].

The present data show a significant increase in erythrocyte numbers, hematocrit and hemoglobin concentrations in Reg-WPS group. In addition, we found a significant difference in the three aforementioned hematological parameters between Occ-WPS and Reg-WPS groups. These findings are indicative of a bone marrow response, causing an increase in red blood cells. We also found that occasional smoking did not provoke such changes. The latter is consistent with a previous study conducted on rats following WPS exposure which showed a significant increase in red blood cells count, hemoglobin concentrations and hematocrit in rats exposed to WPS [59]. In accordance with our findings, a clinical study showed chronic smoking induces increase in red blood cells count, hemoglobin, hematocrit [60].

We also found a significant increase in plasma LDH activity in Reg-WPS exposed mice compared with either the control or Occ-WPS groups. A clinical study conducted on smokers showed high levels of LDH in the plasma [61]. Moreover, we have demonstrated earlier that LDH is increased following short- and long-term exposure to WPS [42, 62, 63]. High levels of LDH in the plasma are usually associated with cell damage caused by smoking [31].

Our data show that Occ-WPS smoking for a period of 6 month did not cause systemic inflammation as no significant changes in the concentrations of IL-1 $\beta$ and TNF $\alpha$ have been observed. By contrast, chronic exposure to Reg-WPS triggered a significant augmentation in the concentration of both pro-inflammatory cytokines. In addition, there was a statistical significance in the concentration of these cytokines between Occ-WPS and Reg-WPS groups. Our findings are consistent with a previous clinical study that showed a significant increase in the levels IL-6, IL-8, IL-1 $\beta$ and TNF $\alpha$ in human plasma following exposure to CS, WPS and dual WPS and CS [64]. The inflammation in the blood suggests that the use of WPS may be a potential risk factor for developing both chronic respiratory and cardiovascular diseases. Moreover, it has been shown that cigarette smoke media stimulates TNF $\alpha$ release by macrophages in vitro [65]. Likewise, we have shown an increase in the concentrations of pro-inflammatory cytokines in the lung and the heart tissue homogenates following WPS exposure $[42,62]$.

It is well recognized that cigarette smoke and WPS contain many oxidants [66]. Hence, it is well established that the adverse effects of smoking may result at least partly from oxidative damage to cellular components [66]. Such damage could result from both oxidants present in cigarette smoke and reactive oxygen species generated from activated phagocytic cells [67]. Unlike proinflammatory markers, both Occ-WPS and Reg-WPS induced a significant increase in the levels of 8-isoprostane and total antioxidant in the plasma. These findings substantiate other studies results that demonstrated the occurrence of oxidative stress following repeated passive [22] and conventional cigarette smoking [68]. In addition, it is well-established that WPS triggers systemic oxidative stress [14]. Moreover, clinically the increase in oxidative stress markers such as 8-epi-prostaglandin F2 $\alpha$ and malondialdehyde has been reported following regular waterpipe smoking [69].

One of the limitations of the current work is the fact that we studied WPS as a whole and it would be relevant to assess the cardiovascular impact of the different components of WPS including the gas and particulate phases. Moreover, the present work has been carried out on healthy mice and it would be important to conduct comparable work on animal models of human diseases including diabetes, hypertension and asthma. 


\section{Cellular Physiology Cell Physiol Biochem 2022;56:13-27

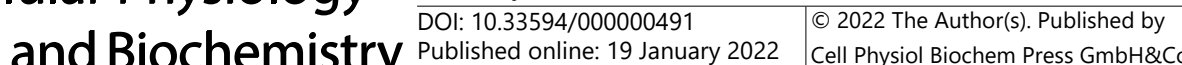 \\ Hamadi et al.: Waterpipe Smoking Regimen and Vascular Responses}

\section{Conclusion}

Taken together, our data confirmed the alteration of vascular homeostasis, systemic inflammation and oxidative stress induced by regular WPS inhalation and it showed, for the first time, that even chronic occasional WPS inhalation caused hypercoagulability, vascular alteration and systemic oxidative stress. The latter findings clearly indicate that more measures of awareness are needed to limit the widely spread misperception that occasional smoking has low risk of smoking-related diseases.

\section{Acknowledgements}

\section{Author Contributions}

$\mathrm{NH}$ contributed to the interpretation of data, drafting and revising the manuscript. SB, NEZ and OE performed the experiments. BHA contributed to the design and the editing of the manuscript. AN designed, planned, supervised all the experiments, analyzed and interpreted the data and edited the manuscript. All authors have approved the final version of the manuscript.

\section{Funding}

This work was supported by funds of the Zayed Center for Health Sciences (grants \# 12R008 and 12R072) and the College of Medicine and Health Sciences (grant \# 12M022) of the United Arab Emirates University and Al-Jalila Foundation (grant \# AJF201701).

\section{Statement of Ethics}

The project was reviewed and approved by the Institutional Animal Care and Use Committee of the United Arab Emirates University (Approval \# ERA_2017_5625) and experiments were performed in accordance with protocols approved by the Institutional Animal Care and Research Advisory Committee.

\section{Disclosure Statement}

The authors declare they have no conflict of interests.

\section{References}

1 Qasim H, Alarabi AB, Alzoubi KH, Karim ZA, Alshbool FZ, Khasawneh FT: The effects of hookah/waterpipe smoking on general health and the cardiovascular system. Environ Health Prev Med 2019;24:58.

2 Martinasek MP, McDermott RJ, Bryant CA: Antecedents of university students' hookah smoking intention. Am J Health Behav 2013;37:599-609.

3 Daradka H, Khabour O, Alzoubi K, Nakkash R, Eissenberg T: Tobacco and waterpipe use among university students in Saudi Arabia: impact of tobacco sales ban. East Mediterr Health J 2019;25:111-118.

4 Alomari MA, Al-Sheyab NA, Khabour OF, Alzoubi KH: Brain-derived neutrophic factor in adolescents smoking waterpipe: The Irbid TRY. Int J Dev Neurosci 2018;67:14-18.

5 Almogbel YS, Aladhadh T, Alammar A, Aloraini A, Alghofaili S, Almutairi A, AlAmri A: Predictors of waterpipe smoking among university students in the Qassim region, Saudi Arabia. Tob Induc Dis 2021;19:67.

6 Shihadeh A: Investigation of mainstream smoke aerosol of the argileh water pipe. Food Chem Toxicol 2003;41:143-152.

7 Neergaard J, Singh P, Job J, Montgomery S: Waterpipe smoking and nicotine exposure: a review of the current evidence. Nicotine Tob Res 2007;9:987-994. 


\section{Cellular Physiology Cell Physiol Biochem 2022;56:13-27 \begin{tabular}{ll|l|l|l} 
DOI: 10.33594/000000491 2022 The Author(s). Published by \\
and Biochemistry Published
\end{tabular} and Biochemistry Published online: 19 January 2022 Cell Physiol Biochem Press GmbH\&Co. KG \\ Hamadi et al.: Waterpipe Smoking Regimen and Vascular Responses}

8 Joseph R, Alshayban D: Changes in Attitude to Waterpipe Tobacco Smoking among Youngsters in Eastern Province, Saudi Arabia: A Cross-Sectional Study. Asian Pac J Cancer Prev 2021;22:1443-1450.

9 Schubert J, Müller FD, Schmidt R, Luch A, Schulz TG: Waterpipe smoke: source of toxic and carcinogenic VOCs, phenols and heavy metals? Arch Toxicol 2015;89:2129-2139.

10 Shihadeh A, Schubert J, Klaiany J, El Sabban M, Luch A, Saliba NA: Toxicant content, physical properties and biological activity of waterpipe tobacco smoke and its tobacco-free alternatives. Tob Control 2015;24:i22-i30.

11 Al-Shatnawi SF, Alzoubi KH, Khabour OF: Withdrawal Symptoms among Cigarette and Waterpipe Smokers: A Study in Natural Setting. Clin Pract Epidemiol Ment Health 2021;17:114-120.

12 El-Zaatari ZM, Chami HA, Zaatari GS: Health effects associated with waterpipe smoking. Tob Control 2015;24:i31-i43.

13 Ali BH, Al Balushi KA, Ashique M, Shalaby A, Al Kindi MA, Adham SA, Karaca T, Beegam S, Yuvaraju P, Nemmar A: Chronic Water-Pipe Smoke Exposure Induces Injurious Effects to Reproductive System in Male Mice. Front Physiol 2017;8:158.

14 Rababa'h AM, Mardini AN, Ababneh MA, Alzoubi KH: Waterpipe tobacco smoke and health: What we have learned from rodent models? Life Sci 2021;284:119898.

15 Kaur J: A comprehensive review on metabolic syndrome. Cardiol Res Pract 2014;2014:943162.

16 Shafique K, Mirza SS, Mughal MK, Arain ZI, Khan NA, Tareen MF, Ahmad I: Water-pipe smoking and metabolic syndrome: a population-based study. PLoS One 2012;7:e39734.

17 Tamim H, Yunis KA, Chemaitelly H, Alameh M, Nassar AH: Effect of narghile and cigarette smoking on newborn birthweight. BJOG: Int J Obs Gyn 2008;115:91-97.

18 Nuwayhid IA, Yamout B, Azar G, Kambris MA: Narghile (hubble-bubble) smoking, low birth weight, and other pregnancy outcomes. Am J Epidemiol 1998;148:375-383.

19 Khabour OF, Alzoubi KH, Al-Sheyab N, Shihadeh A, Eissenberg T: Investigating the Effects of Exposure to Waterpipe Smoke on Pregnancy Outcomes Using an Animal Model. Nicotine Tob Res 2016;18:585-589.

20 Jensen PD, Cortes R, Engholm G, Kremers S, Gislum M: Waterpipe use predicts progression to regular cigarette smoking among Danish youth. Subst Use Misuse 2010;45:1245-1261.

21 Shiffman S, Dunbar MS, Kirchner TR, Li X, Tindle HA, Anderson SJ, Scholl SM, Ferguson SG: Cue reactivity in non-daily smokers: effects on craving and on smoking behavior. Psychopharmacology 2013;226:321-333.

22 Ahmadzadehfar H, Oguogho A, Efthimiou Y, Kritz H, Sinzinger H: Passive cigarette smoking increases isoprostane formation. Life Sci 2006;78:894-897.

23 Hobkirk AL, Midya V, Krebs NM, Allen SI, Reinhart L, Sun D, Stennett AL, Muscat JE: Characterizing nicotine exposure among a community sample of non-daily smokers in the United States. BMC Public Health 2021;21:1025.

24 Branstetter SA, Nye RT, Muscat JE: Time to first cigarette of the day and 4-(methylnitrosamino)-1-(3pyridyl)-1-butanol (NNAL) in adult regular and non-daily smokers: (NHANES) 2007-10. Regul Toxicol Pharmacol 2019;108:104454.

25 Oksuz E, Mutlu ET, Malhan S: Characteristics of daily and occasional smoking among youths. Public Health 2007;121:349-356.

26 Patton GC, Hibbert M, Rosier MJ, Carlin JB, Caust J, Bowes G: Is smoking associated with depression and anxiety in teenagers? Am J Public Health 1996;86:225-230.

27 Alomari MA, Khabour OF, Alzoubi KH, Eissenberg T: Puffing topography and physiological responses in men and women with low versus high waterpipe dependence during smoking: The WiHi Irbid project. Drug Alcohol Depend 2020;212:108037.

28 Keller-Hamilton B, Mehta T, Hale JJ, Leavens ELS, Shihadeh A, Eissenberg T, Brinkman MC, Wagener TL: Effects of flavourants and humectants on waterpipe tobacco puffing behaviour, biomarkers of exposure and subjective effects among adults with high versus low nicotine dependence. Tob Control 2021; DOI: 10.1136/tobaccocontrol-2020-056062.

29 Khabour OF, Alsatari ES, Azab M, Alzoubi KH, Sadiq MF: Assessment of genotoxicity of waterpipe and cigarette smoking in lymphocytes using the sister-chromatid exchange assay: a comparative study. Environ Mol Mutagen 2011;52:224-228.

30 Schane RE, Ling PM, Glantz SA: Health effects of light and intermittent smoking: a review. Circulation 2010;121:1518-1522. 


\section{Cellular Physiology Cell Physiol Biochem 2022;56:13-27 \begin{tabular}{l|l} 
DOI: 10.33594/000000491 & (c) 2022 The Author(s). Published by
\end{tabular} and Biochemistry Published online: 19 January 2022 Cell Physiol Biochem Press GmbH\&Co. KG \\ Hamadi et al.: Waterpipe Smoking Regimen and Vascular Responses}

31 Gutiérrez-Torres DS, Wang L, Blount BC, Xia B, Sosnoff CS, Shiels MS, Inoue-Choi M, Etemadi A, Freedman ND: Concentrations of Cotinine and 4-(Methylnitrosamino)-1-(3-Pyridyl)-1-Butanol (NNAL) in U.S. NonDaily Cigarette Smokers. Cancer Epidemiol Biomarkers Prev 2021;30:1165-1174.

32 Nemmar A, Yuvaraju P, Beegam S, John A, Raza H, Ali BH: Cardiovascular effects of nose-only water-pipe smoking exposure in mice. Am J Physiol Heart Circ Physiol 2013;305:740-746.

33 Nemmar A, Al-Salam S, Yuvaraju P, Beegam S, Yasin J, Ali BH: Chronic exposure to water-pipe smoke induces cardiovascular dysfunction in mice. Am J Physiol Heart Circ Physiol 2017;312:H329-H339.

34 Hassmiller KM, Warner KE, Mendez D, Levy DT, Romano E: Nondaily smokers: who are they? Am J Public Health 2003;93:1321-1327.

35 Inoue-Choi M, McNeel TS, Hartge P, Caporaso NE, Graubard BI, Freedman ND: Non-Daily Cigarette Smokers: Mortality Risks in the U.S. Am J Prev Med 2019;56:27-37.

36 Matetzky S, Tani S, Kangavari S, Dimayuga P, Yano J, Xu H, Chyu KY, Fishbein MC, Shah PK, Cercek B: Smoking increases tissue factor expression in atherosclerotic plaques: implications for plaque thrombogenicity. Circulation 2000;102:602-604.

37 Alarabi AB, Karim ZA, Ramirez JEM, Hernandez KR, Lozano PA, Rivera JO, Alshbool FZ, Khasawneh FT: Short-Term Exposure to Waterpipe/Hookah Smoke Triggers a Hyperactive Platelet Activation State and Increases the Risk of Thrombogenesis. Arterioscler Thromb Vasc Biol 2020;40:335-349.

38 Qasim H, Karim ZA, Silva-Espinoza JC, Khasawneh FT, Rivera JO, Ellis CC, Bauer SL, Almeida IC, Alshbool FZ: Short-Term E-Cigarette Exposure Increases the Risk of Thrombogenesis and Enhances Platelet Function in Mice. J Am Heart Assoc 2018;7:e009264

39 Ramirez JEM, Karim ZA, Alarabi AB, Hernandez KR, Taleb ZB, Rivera JO, Khasawneh FT, Alshbool FZ: The JUUL E-Cigarette Elevates the Risk of Thrombosis and Potentiates Platelet Activation. J Cardiovasc Pharmacol Ther 2020;25:578-586.

40 Nemmar A, Yuvaraju P, Beegam S, Ali BH: Short-term nose-only water-pipe (shisha) smoking exposure accelerates coagulation and causes cardiac inflammation and oxidative stress in mice. Cell Physiol Biochem 2015;35:829-840.

41 Yu R, Deochand C, Krotow A, Leão R, Tong M, Agarwal AR, Cadenas E, De la Monte SM: Tobacco Smoke-Induced Brain White Matter Myelin Dysfunction: Potential Co-Factor Role of Smoking in Neurodegeneration. J Alzheimers Dis 2016;50:133-148.

42 Nemmar A, Al-Salam S, Beegam S, Yuvaraju P, Zaaba NE, Yasin J, Ali BH: Waterpipe Tobacco Smoke Inhalation Triggers Thrombogenicity, Cardiac Inflammation and Oxidative Stress in Mice: Effects of Flavouring. Int J Mol Sci 2020;21:1291.

43 Ambrus JL, Mink IB: Effect of cigarette smoking on blood coagulation. Clin Pharmacol Ther 1964;5:428431.

44 Nielsen VG, Hafner DT, Steinbrenner EB: Tobacco smoke-induced hypercoagulation in human plasma: role of carbon monoxide. Blood Coagul Fibrinolysis 2013;24:405-410.

45 Barua RS, Ambrose JA: Mechanisms of coronary thrombosis in cigarette smoke exposure. Arterioscler Thromb Vasc Biol 2013;33:1460-1467.

46 Pamukcu B, Oflaz H, Onur I, Cimen A, Nisanci Y: Effect of cigarette smoking on platelet aggregation. Clin Appl Thromb Hemost 2011;17:E175-180.

47 Larsen GR, Sako D, Ahern TJ, Shaffer M, Erban J, Sajer SA, Gibson RM, Wagner DD, Furie BC, Furie B: P-selectin and E-selectin. Distinct but overlapping leukocyte ligand specificities. J Biol Chem 1992;267:11104-11110.

48 Milstone DS, O’Donnell PE, Stavrakis G, Mortensen RM, Davis VM: E-selectin expression and stimulation by inflammatory mediators are developmentally regulated during embryogenesis. Lab Invest 2000;80:943954.

49 Chen HW, Lii CK, Ku HJ, Wang TS: Cigarette smoke extract induces expression of cell adhesion molecules in HUVEC via actin filament reorganization. Environ Mol Mutagen 2009;50:96-104.

50 Mobarrez F, Antoniewicz L, Hedman L, Bosson JA, Lundbäck M: Electronic cigarettes containing nicotine increase endothelial and platelet derived extracellular vesicles in healthy volunteers. Atherosclerosis 2020;301:93-100.

51 Alamanda V, Singh S, Lawrence NJ, Chellappan SP: Nicotine-mediated induction of E-selectin in aortic endothelial cells requires Src kinase and E2F1 transcriptional activity. Biochem Biophys Res Commun 2012;418:56-61. 


\section{Cellular Physiology Cell Physiol Biochem 2022;56:13-27

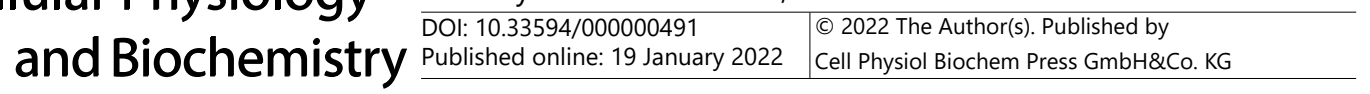 \\ Hamadi et al.: Waterpipe Smoking Regimen and Vascular Responses}

52 Makwana O, Smith GA, Flockton HE, Watters GP, Lowe F, Breheny D: Impact of cigarette versus electronic cigarette aerosol conditioned media on aortic endothelial cells in a microfluidic cardiovascular model. Sci Rep 2021;11:4747.

53 Alomari MA, Al-Sheyab NA, Khabour OF, Alzoubi KH: Serum VEGF Level Is Different in Adolescents Smoking Waterpipe versus Cigarettes: The Irbid TRY. Biomolecules 2018;8:102.

54 Cirillo P, S DER, Pacileo M, Gargiulo A, Leonardi A, Angri V, Formisano S, Chiariello M: Nicotine induces tissue factor expression in cultured endothelial and smooth muscle cells. J Thromb Haemost 2006;4:453458.

55 Hu XY, Ma YH, Wang C, Yang YH: Effects of simvastatin on cigarette smoke extract induced tissue-type plasminogen activator and plasminogen activator inhibitor-1 expression in human umbilical vein endothelial cells. Chin Med J (Engl) 2009;122:2380-2385.

56 Simpson AJ, Gray RS, Moore NR, Booth NA: The effects of chronic smoking on the fibrinolytic potential of plasma and platelets. Br J Haematol 1997;97:208-213.

57 Newby DE, McLeod AL, Uren NG, Flint L, Ludlam CA, Webb DJ, Fox KA, Boon NA: Impaired coronary tissue plasminogen activator release is associated with coronary atherosclerosis and cigarette smoking: direct link between endothelial dysfunction and atherothrombosis. Circulation 2001;103:1936-1941.

58 Sezavar SH, Abedi A, Sadeghi BH: A comparative study of plasma fibrinogen among hookah smokers, cigarette smokers and non-smokers. Iran Heart J 2004;5:48-54.

59 Miri-Moghaddam E, Mirzaei R, Arab MR, Kaikha S: The effects of water pipe smoking on hematological parameters in rats. Int J Hematol Oncol Stem Cell Res 2014;8:37-43.

60 Malenica M, Prnjavorac B, Bego T, Dujic T, Semiz S, Skrbo S, Gusic A, Hadzic A, Causevic A: Effect of Cigarette Smoking on Haematological Parameters in Healthy Population. Med Arch 2017;71:132-136.

61 Raddam QN, Zeidan M, K.Asaad N, Abdulrahman M: Smoking Effects on Blood Antioxidants Level: Lactate Dehydrogenase, Catalase, Superoxide Dismutase and Glutathione Peroxidase in University Students. J Clin Exp Pathol 2017;7:1-6.

62 Nemmar A, Al Hemeiri A, Al Hammadi N, Yuvaraju P, Beegam S, Yasin J, Elwasila M, Ali BH, Adeghate E: Early pulmonary events of nose-only water pipe (shisha) smoking exposure in mice. Physiol Rep 2015;3:12258.

63 Nemmar A, Al-Salam S, Yuvaraju P, Beegam S, Yasin J, Ali BH: Chronic Exposure to Water-Pipe Smoke Induces Alveolar Enlargement, DNA Damage and Impairment of Lung Function. Cell Physiol Biochem 2016;38:982-992.

64 Khan NA, Lawyer G, McDonough S, Wang Q Kassem NO, Kas-Petrus F, Ye D, Singh KP, Kassem NO, Rahman I: Systemic biomarkers of inflammation, oxidative stress and tissue injury and repair among waterpipe, cigarette and dual tobacco smokers. Tob Control 2020;29:s102-s109.

65 Demirjian L, Abboud RT, Li H, Duronio V: Acute effect of cigarette smoke on TNF-alpha release by macrophages mediated through the erk1/2 pathway. Biochim Biophys Acta 2006;1762:592-597.

66 Badran M, Laher I: Waterpipe (shisha, hookah) smoking, oxidative stress and hidden disease potential. Redox Biol 2020;34:101455.

67 Church DF, Pryor WA: Free-radical chemistry of cigarette smoke and its toxicological implications. Environ Health Perspect 1985;64:111-126.

68 Morrow JD, Frei B, Longmire AW, Gaziano JM, Lynch SM, Shyr Y, Strauss WE, Oates JA, Roberts LJ: Increase in circulating products of lipid peroxidation (F2-isoprostanes) in smokers. Smoking as a cause of oxidative damage. N Engl J Med 1995;332:1198-1203.

69 Wolfram RM, Chehne F, Oguogho A, Sinzinger H: Narghile (water pipe) smoking influences platelet function and (iso-)eicosanoids. Life Sci 2003;74:47-53. 